silicon, although gold is perhaps one of the best known and widely used deep level impurity centres.

\section{Acknowledgements}

The author would like to acknowledge the invaluable contributions to the development of the concepts described here by his former thesis advisor at the University of Illinois, Professor C. T. Sah, and his continued interest and collaboration in work since that time. Some of the results summarised here have been taken from the author's Ph.D. thesis at the University of Illinois, work which was supported by the U.S. Air Force Office of Scientific Research and Defense Advanced Research Projects Agency. Other results have been summarised from work in conjunction with W. C. Parker at the University of Arkansas, the latter and this work at the University of California at Davis have also been supported by the Defense Advanced Research Projects Agency.

\section{References}

1 C. B. Collins, R. O. Carlson and C. J. Gallagher, Phys. Rev., 1957, 105, 1168

2 W. M. Bullis, Solid-State Electron., 1957, 9, 143

3 C. T. Sah, Proc. IEEE, 1967, 55, 654

4 L. Forbes, 'Thermal and Optical Emission and Thermal Capture of Electrons and Holes at Gold Centers in Silicon,' Ph.D. Thesis, University of Illinois, Urbana, Illinois, U.S.A., 1970

5 C. T. Sah, L. Forbes, L. L. Rosier and A. F. Tasch, Solid-State Electron., 1970, 13, 759

6 W. C. Parker and L. Forbes, IEEE Trans, on Electron Devices, 1975, ED-22, 916

7 C. T. Sah, Solid-State Electronics, 1976, 19, 975

$8 \mathrm{~J}, \mathrm{M}$. Fairfield and B. V. Gokhale, Solid-State Electron., $1965,8,685$

9 C. T. Sah, L. Forbes, L. L. Rosier, A. F. Tasch and A. B. Tole, Appl. Phys, Lett., 1969, 15, 145

\title{
The Electroless Deposition of Gold
}

\section{INFLUENCE OF THE SUBSTRATE STRUCTURE}

Many types of electroless gold deposition processes have been proposed over the past fifteen years or so, but there is little doubt that the most successful solution was that devised in 1969 by Y. Okinaka at Bell Telephone Laboratories. This is based upon the use of an alkali metal borohydride, and it has found a number of applications in the fabrication of electronic components, although the process is still regarded as being complementary to, rather than competitive with, normal methods of electrodeposition, particularly where its catalytic characteristic is essential. Furthermore it has been the subject of intense investigation over the intervening years, both in respect of its mechanism of operation and of the structure and properties of the deposits (1).

The Okinaka bath is capable of producing sound if rather soft deposits of high purity gold, but the degree of porosity to be expected varies appreciably with their crystal structure, and this in turn depends largely upon the crystallographic orientation of the substrate as well as on the conditions of deposition.

The most recent paper by two of Dr. Okinaka's colleagues, R. Sard and B. C. Wonsiewicz (2) shows that the orientation of the metal substrate may in fact have a profound effect on both the kinetics of the process and the structure of the deposits. The structure of gold deposits on single crystals of copper was studied at several stages of growth by means of a computer-aided $\mathrm{X}$-ray pole figure technique, while additional data were secured by both transmission and scanning electron microscopy examination of the deposits. It was found that the initial rate of deposition could vary by an order of magnitude, the rate on $\{111\}$ greatly exceeding that on $\{100\}$, which in turn gave a higher rate than on the $\{110\}$ orientation.

In the early stages of deposition growth was epitaxial, but after a few minutes complex multiple twinning began to occur, and appeared to be responsible for a transition from the initially slow rate of deposition to the faster rate typical of the $\{111\}$ orientation.

Deposition on polycrystalline substrates, including commercial copper strip, in both the cold rolled and the annealed conditions, was found to be in fairly

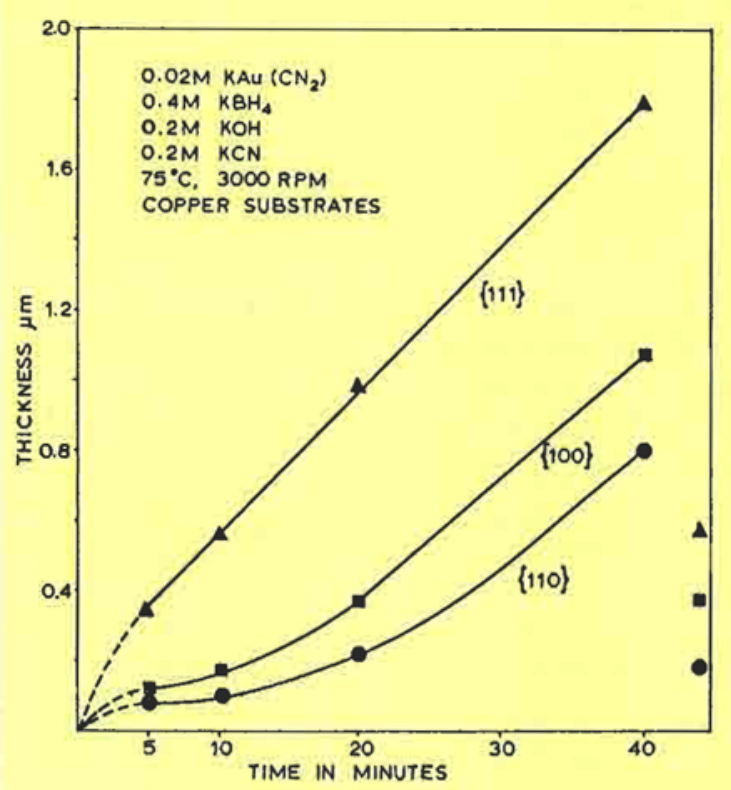

The effect of crystal orientation on the rate of deposition of gold in the Okinaka electroless process. The initial rate of deposition is seen to be highly orientation dependent

general agreement with the results obtained on single crystals. The authors conclude that the substrate effects demonstrated in this work could be of equal importance in other catalytic methods of metal deposition and that this should prove to be a fruitful area for further research.

\section{Referenees}

1 Y. Okinaka, in "Gold Plating Technology", ed. F. H. Reid and W. Goldie, Ayr, 1973, pp, 82-102; W. S. Rapson and T. Groenwald, Gold Bull., 1975, 8, (4), 119-126

2 R. Sard and B. C. Wonsiewicz, F. Electrochem. Soc., 1976, 123, (11), 1604-1612 